V Seminário Anual Científico e Tecnológico | Bio-Manguinhos

\title{
VAC 04 - Teste de ativação de monócitos para monitoramento da atividade pirogênica na vacina de febre amarela
}

Vítor Fernandes Silva1; Alessandra Santos Almeida1*; Elaine Cristina Azevedo Navega1; Cristiane Caldeira da Silva2; Octávio Augusto França Presgrave2; Isabella Fernandes Delgado2; Katherine Antunes de Mattos1.

1Bio-Manguinhos / Fiocruz;

2INCQS / Fiocruz.

\section{Introdução:}

O controle total da qualidade em produtos farmacêuticos encerra o esforço organizado de uma empresa com o escopo manter e assegurar as características especificas unitárias do produto distribuído para comercialização. Nesse contexto, é mandatório que os agentes parenterais de uso humano e animal tenham sua atividade pirogênica monitorada. Em consonância com a tendência mundial de substituição do uso de animais, o Teste de Ativação de Monócitos (MAT) foi aceito pela Farmacopeia Europeia como método in vitro que utiliza matriz monocítica humana para detecção de pirogênios. O MAT supre limitações dos testes pirogênicos atuais: o Teste de Endotoxina Bacteriana (LAL) e o Teste de Pirogenia em coelhos.

\section{Objetivo:}

Investigar fontes pirogênicas diversas não detectáveis pelo método descrito na monografia da vacina de febre amarela (VFA). Foram avaliados, pelo método do MAT, 3 lotes de VFA produzidos por Bio-Manguinhos.

\section{Metodologia:}

Os sistemas do MAT combinaram a utilização de matrizes monocíticas (sangue total fresco e criopreservado) e a detecção de citocinas pró-inflamatórias (IL-6 e IL-1 $\beta$ ) como parâmetros de leitura. Lipopolissacarídeo (LPS), ácido lipoteicóico (LTA) e zymozan A (ZA) foram utilizados como padrões moleculares associados à pirogenia de Gramnegativas, positivas e fungos, respectivamente. Foram avaliados lotes de VFA-10 doses produzidos por Bio-Manguinhos. Estes foram incubados em contato com a matriz monocítica em estufa de $\mathrm{CO} 2$ a $37^{\circ} \mathrm{C}$ e após 16 horas foram quantificadas IL-1 $\beta$ e IL-6 
pelo ensaio de ELISA (R\&D Systems). Em paralelo, os lotes foram analisados frente ao método farmacopeico que detecta apenas endotoxina, o LAL.

\section{Resultado:}

A validação produto específica, VFA frente ao MAT, mostra aplicabilidade do teste ao produto utilizando diluições 1:10. O sistema foi capaz de identificar NEPs (LTA e ZA) exógenos na presença de VFA. Análises estatísticas demonstraram uma boa correlação entre os sistemas de leituras (IL-1 $\beta$ e IL-6) para curvas de LPS em salina ( $r=0.9956$ and $\mathrm{p}<0.0001)$ e em VFA ( $r=0.9972$ and $\mathrm{p}=0.0028)$. Os ensaios de linhas paralelas das curvas de LPS e LTA em salina versus VFA demonstraram que o P-valor para o não-paralelismo não foi significante para IL-1 $\beta$ e IL-6 ( $p$ > 0,05). Os ensaios quantitativos demonstraram que os lotes foram considerados não-pirogênicos, reforçando os resultados obtidos pelo LAL, respeitando assim, os parâmetros específicos da monografia do produto.

\section{Conclusão:}

O presente estudo demonstrou a susceptibilidade da VFA à análise pelo MAT, observando uma correlação positiva com LAL e a análise diferencial e quantitativa de NEPs como potenciais alvos de contaminação na indústria. Os resultados reforçam a possibilidade da redução de animais para fins industriais, atendendo à tendência mundial, além de um controle investigativo e preventivo de contaminantes outros não identificados pelo método atual, oferecendo um controle adicional aos produtos do portfólio de BioManguinhos.

Palavras-chave: Teste de Ativação de Monócitos; Vacina de Febre Amarela; Métodos Alternativos 